\title{
Modifications in the glycerophospholipid composition between the Coxiella burnetii phase I and phase II cells suggest an association with phase variation of the bacterium
}

\author{
M. FRIMMELOVÁ ${ }^{1}$, R. TOMAN ${ }^{1}$, P. POMPACH ${ }^{2,3}$, L. ŠKULTÉTY ${ }^{1,2 *}$
}

\begin{abstract}
${ }^{1}$ Institute of Virology, Biomedical Research Center, Slovak Academy of Sciences, Dúbravská cesta 9, 84505 Bratislava, Slovak Republic; ${ }^{2}$ Institute of Microbiology of the ASCR, v. v. i., Vídenská 1083, 14220 Prague 4, Czech Republic; ${ }^{3}$ Department of Biochemistry, Faculty of Sciences, Charles University, Prague, Czech Republic
\end{abstract}

Received June 1, 2015; accepted January 25, 2016

\begin{abstract}
Summary. - Glycerophospholipids (GP) extracted from the Coxiella burnetii strain Nine Mile in virulent phase I (NM I) and low virulent phase II (NM II) were analyzed by Fourier transform ion cyclotron resonance (FT-ICR) mass spectrometry (MS) that gave a superior mass resolution and mass accuracy allowing unambiguous peak recognition and precise assignment of ions. We showed that GP present in the pathogen's outer membrane underwent considerable modifications during the phase variation that might be related to impact of various environmental factors. It was found that GP from phase I cells were much more complex than those from phase II cells. While glycerophosphoethanolamines (PE), glycerophosphocholines (PC) and glycerophosphoglycerols (PG) were present in both phases of C. burnetii, major differences were observed in the presence of glycerophosphates (PA) and glycerophosphoserines (PS). Thus, PA but no PS were detected in NM I variant in contrast with NM II cells where PS but no PA were identified. It is suggested that enzymes for PA head group modifications to form PS, PE, and PG become active during the phase variation of the bacterium.
\end{abstract}

Keywords: Coxiella burnetii; glycerophospholipids; FT-ICR MS

\section{Introduction}

Coxiella burnetii is the etiological agent of Q fever, a zoonosis which is capable of being transmitted from animals to humans and which is endemic throughout the world (Marrie and Raoult, 1997; Arricau-Bouvery and Rodolakis, 2005). The most common acute form of the disease is manifested in humans as a self-limited febrile illness or pneumonia, or

*Corresponding author. E-mail: viruludo@savba.sk; phone: +4212-59302-418.

Abbreviations: $\mathrm{CL}=$ cardiolipin; FT-ICR $=$ Fourier transform ion cyclotron resonance; GP = glycerophospholipids; $\mathrm{MS}=$ mass spectrometry; $m / z=$ mass-to-charge ratio; $\mathrm{NM} \mathrm{I} \mathrm{=} \mathrm{strain} \mathrm{Nine}$ Mile in virulent phase I; NM II = strain Nine Mile in low virulent phase II; PA = glycerophosphates; $\mathrm{PC}=$ glycerophosphocholines; $\mathrm{PE}=$ glycerophosphoethanolamines; $\mathrm{PG}=$ glycerophosphoglycerols; $\mathrm{PL}=$ phospholipids; $\mathrm{PS}=$ glycerophosphoserines less frequently as hepatitis. Persistent infection can lead to a chronic form of Q fever, which may be associated with a fatal endocarditis (Marrie and Raoult, 1997). In animals, $\mathrm{Q}$ fever affects livestock and is associated with pneumonia and reproductive disorders like abortion, stillbirth, placentitis, endometritis and infertility (Arricau-Bouvery and Rodolakis, 2005).

C. burnetii, an obligate intracellular parasite of eukaryotic cells, is a pleomorphic coccobacillus with a gram-negative cell wall (Baca and Paretsky, 1983). The envelope surrounding C. burnetii is comprised of two membranes (McCaul and Williams, 1981). Both leaflets of the inner membrane are composed of phospholipids (PL), while the outer leaflet of the outer membrane is dominated in naturally occurring virulent phase I cells by a lipopolysaccharide (LPS) that is considered to be one of the major factors of virulence expression and infection of the bacterium (Toman et al., 2009). The primary function of PL is the formation of a semipermeable 
diffusion barrier which allows the intracellular accumulation of metabolites in physiologically relevant concentrations, selective uptake of nutrients, defined release of secretory molecules, and prevention of entry of harmful substances (Cronan, 2003). The PL composition of the membrane is crucial for bacteria to cope with environmental hazards such as extreme $\mathrm{pH}$, high osmolarity, or exposure to surfactant molecules (Kuhn et al., 2015). Moreover, PL are involved in bacterial infection as they represent both, target and barrier for antibiotics and host defense mechanisms such as cationic antimicrobial peptides and enzymes produced by phagocytes or epithelial cells (Kraus and Peschel, 2008).

Despite an important role PL play in the live cycle/survival of C. burnetii in host cells, data on their composition are scarce. It is well known that the bacterium occurring in nature in virulent phase I changes to low virulent phase II upon serial passages in a culture medium. This phase variation is connected with modifications in both composition and structure of the C. burnetii LPS, proteins and PL (Narasaki and Toman, 2012; Skultety et al., 2011; Domingues et al., 2002). The phenomenon has a noticeable impact on biological properties of the bacterium but is still poorly understood. In the past, we published the first report on the composition of glycerophospholipids (GP) isolated from virulent and low virulent cells of C. burnetii (Domingues et al., 2002). Using fast atom bombardment (FAB) mass spectrometry (MS) we detected six GP classes in virulent and five classes in low virulent cells. In addition, we showed that composition of GP within the individual classes was much more complex in virulent than in low virulent cells. It appeared that a more detailed identification and characterization of these biopolymers would enable to better understand their structural and functional peculiarities and their role in pathogenesis and immunity of $\mathrm{Q}$ fever. Fourier transform ion-cyclotron resonance (FT-ICR) MS is a perfect tool in this respect. It can provide superior mass resolution and mass accuracy, which allows unambiguous peak recognition and precise assignment of exact masses. Thus, it allows identification of molecular formulae with increased confidence. We have used this technique for further, more detailed analysis of GP from C. burnetii. The results are reported herein.

\section{Materials and Methods}

Cultivation and purification of C. burnetii strains. C. burnetii strains Nine Mile in virulent phase I (NM I) and low virulent phase II (NM II) were obtained from the strain collection of the Laboratory for Diagnosis and Prevention of Rickettsial and Chlamydial Infections, Institute of Virology, Slovak Academy of Sciences, Bratislava, Slovak Republic. Both strains were propagated in embryonated, antibiotic-free, and pathogen-free hen eggs as described earlier (Toman and Škultéty, 1996; Škultéty et al., 1998).
All laboratory procedures involving the handling of live bacteria were carried out at Biosafety level 3. The propagated bacteria were inactivated with $0.5 \%$ phenol and purified by rate-zonal sedimentation in gradients of Renografin as described previously (Fodorova et al., 2011).

Isolation of PL. PL were extracted from the NM I and NM II cells with chloroform-methanol $(2: 1, \mathrm{v} / \mathrm{v})$ at $20^{\circ} \mathrm{C}$ overnight (Folch et al., 1957). The cells were separated by low-speed centrifugation $(9,300$ $\mathrm{x} g$ for $10 \mathrm{~min}$ ) and extracted again with the chloroform-methanol mixture at $20^{\circ} \mathrm{C}$ for $2 \mathrm{hr}$. After centrifugation, the PL extracts were combined, evaporated to dryness and stored at $+5^{\circ} \mathrm{C}$.

Direct infusion FT-ICR MS. Following the Folch extraction in triplicate preparations, $10 \mathrm{mg}$ of each dry sample were dissolved in $100 \mu \mathrm{l}$ of a mixture of methanol-chloroform (50:50 v/v). To reduce ionization suppression or enhancement effects, each lipid extract $(20 \mu \mathrm{l})$ was then diluted with $180 \mu \mathrm{l}$ of $90 \%$ acetonitrile containing $0.2 \%$ formic acid. The solutions were infused through a syringe pump (KDS Scientific, USA) at a flow rate of $2.0 \mu \mathrm{l} /$ min into a 12T-solariX XR FT-ICR mass spectrometer (Bruker Daltonics, USA). Data were acquired in a positive-ion mode using broadband detection with a data acquisition size of $1.024 \mathrm{~kb} / \mathrm{sec}$ and within $m / z 600$ to 900 . Typical electrospray ionization (ESI) mass spectrometer parameters were: a capillary electrospray voltage of $-4500 \mathrm{~V}$, source ion accumulation time of $0.01 \mathrm{sec}$, and collision cell ion accumulation time of $0.2 \mathrm{sec}$. Survey scan mass spectra were averaged from the accumulation of 8 scans per spectrum. The mass spectrometer was externally calibrated using the NaTFA (sodium trifluoroacetate) clusters.

Data processing. Raw MS data were processed using the mMass software package that was freely available online (Strohalm et al., 2010). Monoisotopic peaks corresponding to the isotopic pattern distributions were automatically determined, and those with a signal-to-noise ratio of at least 3 were picked. The peak intensities of all the monoisotopic masses were subsequently normalized to the total ion intensity calculated from a mass spectrum. PL identification was done by searches against Lipid Maps database (website: http://www.lipidmaps.org/) within $10 \mathrm{ppm}$ tolerance across all data. Identities observed at least in two biological samples of at least one of the sample groups (phase I or phase II) were aligned and combined in a table.

\section{Results and Discussion}

Two sets of PL were isolated from highly purified C. burnetii phase I and phase II cells by chloroform-methanol extraction. The extracts were subjected to exact mass measurements in the selected mass range of $m / z 600-900$ by FT-ICR MS (Figs. 1 and 2). To evaluate mass spectra, the open source MS tool mMass was used to search against the Lipid Maps database. The analyses were focused on the identification of major GP classes present in the isolated materials. At first glance, it was evident that GP detected in 
Table 1. Glycerophospholipids found in virulent phase I and low virulent phase II cells of C. burnetii strain Nine Mile

\begin{tabular}{|c|c|c|c|c|c|c|}
\hline Class & Subclass & $\begin{array}{c}\text { Theoretical } \\
\qquad m / z\end{array}$ & $\begin{array}{l}\text { Observed mass } \\
\text { difference ppm }\end{array}$ & Phase I cells ${ }^{\mathrm{a}}$ & Phase II cells $^{\mathrm{a}}$ & Common name ${ }^{b}$ \\
\hline \multirow{12}{*}{ PA } & \multirow{10}{*}{ DiAcPA } & 657.4490 & -2.0 & LMGP10010145 c & & \multirow{2}{*}{ PA(15:0/18:3(9Z,12Z,15Z)) } \\
\hline & & 679.4309 & -2.8 & LMGP10010145 $\mathrm{Na}^{\mathrm{d}}$ & & \\
\hline & & 685.4779 & 1.5 & LMGP10010910 Na & & \multirow{2}{*}{$\mathrm{PA}(16: 0 / 17: 0)$} \\
\hline & & 701.4518 & -7.2 & LMGP10010910 Ke & & \\
\hline & & 671.4646 & -1.8 & LMGP10010975 & & \multirow{2}{*}{ PA(16:0/18:3(9Z,12Z,15Z)) } \\
\hline & & 693.4466 & -2.5 & LMGP10010975 Na & & \\
\hline & & 713.5116 & -1.8 & LMGP10010353 & & \multirow{2}{*}{ PA(18:2(9Z,12Z)/19:1(9Z)) } \\
\hline & & 735.4935 & -2.0 & LMGP10010353 Na & & \\
\hline & & 685.4803 & -2.0 & LMGP10010372 & & \multirow{2}{*}{ PA(18:3(6Z,9Z,12Z)/17:0) } \\
\hline & & 707.4622 & -2.3 & LMGP10010372 Na & & \\
\hline & \multirow{2}{*}{ 1-(1Z-alkenyl),2-AcPA } & 725.5456 & 4.0 & LMGP10030044 Na & & \multirow{2}{*}{$\mathrm{PA}(\mathrm{P}-18: 0 / 19: 0)$} \\
\hline & & 741.5195 & 6.3 & LMGP10030044 K & & \\
\hline \multirow{14}{*}{$\mathrm{PE}$} & \multirow{14}{*}{ DiAcPE } & 686.4755 & -2.0 & LMGP02010374 & LMGP02010374 & \multirow{2}{*}{$\mathrm{PE}(12: 0 / 20: 3(8 Z, 11 Z, 14 Z))$} \\
\hline & & 708.4575 & -2.8 & LMGP02010374 Na & LMGP02010374 Na & \\
\hline & & 670.4442 & 8.5 & LMGP02010394 & & \multirow{2}{*}{$\mathrm{PE}(13: 0 / 18: 4(6 Z, 9 Z, 12 Z, 15 Z))$} \\
\hline & & 692.4262 & 9.3 & LMGP02010394 Na & & \\
\hline & & 700.4912 & 0.0 & LMGP02010459 & & \multirow{2}{*}{ PE(15:0/18:3(6Z,9Z,12Z)) } \\
\hline & & 722.4731 & -1.5 & LMGP02010459 Na & & \\
\hline & & 672.4599 & 9.8 & LMGP02010594 & & \multirow{2}{*}{$\mathrm{PE}(17: 2(9 \mathrm{Z}, 12 \mathrm{Z}) / 14: 1(9 \mathrm{Z}))$} \\
\hline & & 694.4418 & 8.4 & LMGP02010594 Na & & \\
\hline & & 704.5225 & 1.1 & LMGP02010638 & & \multirow{2}{*}{$\mathrm{PE}(18: 1(9 Z) / 15: 0)$} \\
\hline & & 726.5044 & 1.9 & LMGP02010638 Na & & \\
\hline & & 740.5225 & -4.2 & & LMGP02011197 & \multirow[t]{2}{*}{$\mathrm{PE}(18: 1(9 Z) / 18: 3(9 Z, 12 Z, 15 Z))$} \\
\hline & & 762.5044 & -1.5 & & LMGP02011197 Na & \\
\hline & & 714.5068 & -1.5 & LMGP02010659 & & \multirow{2}{*}{$\mathrm{PE}(18: 2(9 \mathrm{Z}, 12 \mathrm{Z}) / 16: 1(9 \mathrm{Z}))$} \\
\hline & & 736.4888 & -1.9 & LMGP02010659 Na & & \\
\hline \multirow{23}{*}{ PC } & \multirow{20}{*}{ DiAcPC } & 692.5225 & 1.0 & LMGP01011246 & & \multirow{3}{*}{$\mathrm{PC}(8: 0 / 21: 0)$} \\
\hline & & 714.5044 & 1.8 & LMGP01011246 Na & & \\
\hline & & 730.4784 & 1.3 & LMGP01011246 K & & \\
\hline & & 678.5068 & 1.1 & LMGP01010414 & LMGP01010414 & \\
\hline & & 700.4888 & 1.7 & LMGP01010414 Na & LMGP01010414 Na & $\operatorname{PC}(11: 0 / 17: 0)$ \\
\hline & & 716.4627 & -0.3 & LMGP01010414 K & LMGP01010414 K & \\
\hline & & 734.5694 & 1.5 & LMGP01010418 & & $\mathrm{PC}(11 \cdot 0 / 21 \cdot 0)$ \\
\hline & & 756.5514 & -0.4 & LMGP01010418 Na & & $10(11.0 / 21.0)$ \\
\hline & & 664.4912 & 1.2 & LMGP01011317 & & $\operatorname{PC}(12 \cdot 0 / 15 \cdot 0)$ \\
\hline & & 686.4731 & 1.5 & LMGP01011317 Na & & $P C(12: 0 / 15: 0)$ \\
\hline & & 726.5068 & -1.4 & LMGP01011332 & & $\operatorname{PC}(12 \cdot 0 / 20 \cdot 4(5787117,147))$ \\
\hline & & 748.4888 & -3.3 & LMGP01011332 Na & & $P C(12.0 / 20: 4(3 Z, 0 Z, 112,14 Z))$ \\
\hline & & 760.5851 & 2.2 & LMGP01011372 & & PC(14.0/20:1(117)) \\
\hline & & 782.5670 & 1.9 & LMGP01011372 Na & & \\
\hline & & 758.5694 & 2.2 & LMGP01011373 & LMGP01011373 & PC(14.0/20.2(117 147)) \\
\hline & & 780.5514 & 1.2 & LMGP01011373 Na & LMGP01011373 Na & 1 \\
\hline & & 718.5381 & 0.6 & LMGP01010535 & & $\operatorname{PC}(15 \cdot 0 / 16 \cdot 1(97))$ \\
\hline & & 740.5201 & -1.0 & LMGP01010535 Na & & (2) \\
\hline & & 712.4912 & -1.8 & & LMGP01011701 & PC(18:4(6Z,9Z,12Z,15Z)/13:0) \\
\hline & & 734.4731 & -2.1 & & LMGP01011701 Na & स \\
\hline & & 774.5796 & 7.5 & & LMGP01040090 & \\
\hline & DialkylPC & 796.5615 & 7.1 & & LMGP01040090 Na & \\
\hline & & 812.5355 & 8.3 & & LMGP01040090 K & \\
\hline
\end{tabular}




\begin{tabular}{|c|c|c|c|c|c|c|}
\hline Class & Subclass & $\begin{array}{c}\text { Theoretical } \\
\qquad m / z\end{array}$ & $\begin{array}{l}\text { Observed mass } \\
\text { difference ppm }\end{array}$ & Phase I cells ${ }^{\mathrm{a}}$ & Phase II cells ${ }^{\mathrm{a}}$ & Common name ${ }^{\mathrm{b}}$ \\
\hline \multirow{10}{*}{ PS } & \multirow{2}{*}{ DiAcPS } & 790.5593 & 2.8 & & LMGP03010134 & \multirow{2}{*}{ PS(14:1(9Z)/22:0) } \\
\hline & & 812.5412 & 1.2 & & LMGP03010134 Na & \\
\hline & \multirow{8}{*}{ 1-alkyl,2-AcPS } & 776.5800 & -0.9 & & LMGP03020012 & \multirow{2}{*}{ PS(O-16:0/20:1(11Z)) } \\
\hline & & 798.5619 & -1.1 & & LMGP03020012 Na & \\
\hline & & 774.5643 & 1.9 & & LMGP03020013 & \multirow{2}{*}{ PS(O-16:0/20:2(11Z,14Z)) } \\
\hline & & 796.5463 & -1.1 & & LMGP03020013 Na & \\
\hline & & 804.6113 & 2.6 & & LMGP03020015 & \multirow{2}{*}{ PS(O-16:0/22:1(11Z)) } \\
\hline & & 826.5932 & -1.2 & & LMGP03020015 Na & \\
\hline & & 802.5956 & 1.9 & & LMGP03020016 & \multirow{2}{*}{ PS(O-16:0/22:2(13Z,16Z)) } \\
\hline & & 824.5776 & -1.3 & & LMGP03020016 Na & \\
\hline \multirow{10}{*}{ PG } & \multirow{10}{*}{ DiAcPG } & 717.4701 & -2.6 & LMGP04010399 & & \multirow{2}{*}{ PG(18:3(9Z,12Z,15Z)/14:0) } \\
\hline & & 739.4521 & -1.4 & LMGP04010399 Na & & \\
\hline & & 745.5014 & -1.8 & LMGP04010955 & & \multirow{2}{*}{ PG(18:3(9Z,12Z,15Z)/16:0) } \\
\hline & & 767.4834 & -2.1 & LMGP04010955 Na & & \\
\hline & & 759.5171 & -0.1 & LMGP04010404 & LMGP04010404 & \multirow{2}{*}{ PG(18:3(9Z,12Z,15Z)/17:0) } \\
\hline & & 781.4990 & 2.4 & LMGP04010404 Na & LMGP04010404 Na & \\
\hline & & 757.5014 & -1.8 & & LMGP04010405 & \multirow{2}{*}{ PG(18:3(9Z,12Z,15Z)/17:1(9Z)) } \\
\hline & & 779.4834 & -2.5 & & LMGP04010405 Na & \\
\hline & & 755.4834 & 2.5 & LMGP04010483 Na & & \multirow{2}{*}{ PG(19:1(9Z)/14:1(9Z)) } \\
\hline & & 771.4573 & 6.3 & LMGP04010483 K & & \\
\hline
\end{tabular}

${ }^{a}$ Lipid Maps Glycerophospholipid (LMGP) Identification Number, ${ }^{a, b}$ Lipid Maps Structure Database (LMSD), http://www.lipidmaps.org/data/databases. html. The ions are in ${ }^{\mathrm{c}}[\mathrm{M}+\mathrm{H}]^{+},{ }^{\mathrm{d}}[\mathrm{M}+\mathrm{Na}]^{+}$, and ${ }^{\mathrm{e}}[\mathrm{M}+\mathrm{K}]^{+}$forms. For abbreviations, see text.

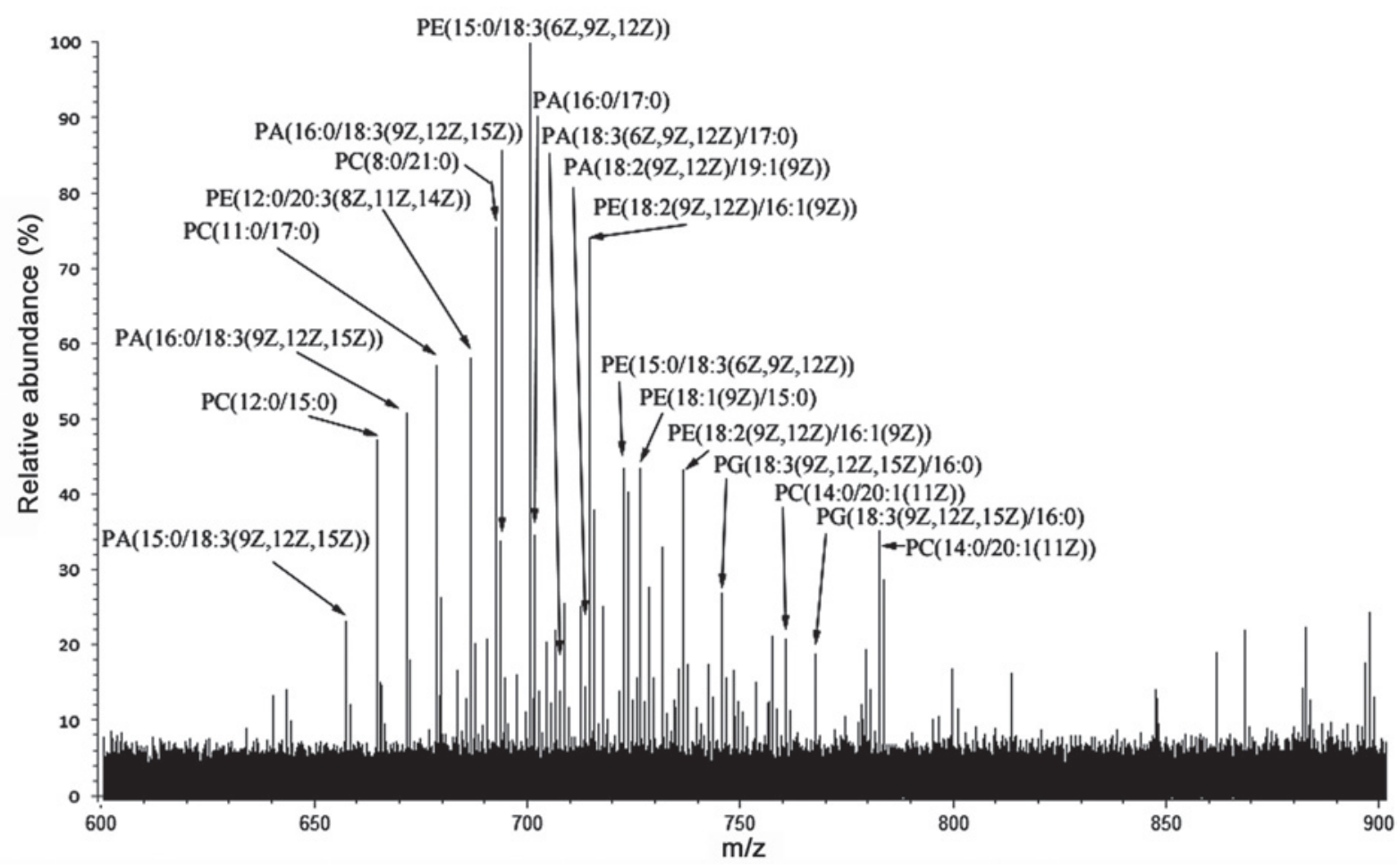

Fig. 1

FT-ICR mass spectrum in the region of $m / z$ 600-900 obtained for chloroform-methanol extract of C. burnetii in virulent phase I The selected ion peaks are labeled with the Common name as given for GP at http://www.lipidmaps.org/data/databases.html. The peaks represent [M + $\mathrm{H}]^{+},[\mathrm{M}+\mathrm{Na}]^{+}$, and $[\mathrm{M}+\mathrm{K}]^{+}$ions. 
virulent $C$. burnetii phase I cells were more complex than those present in low virulent phase II cells. The analyses revealed an absence of the glycerophosphoserines (PS) class in phase I and of glycerophosphates (PA) class in phase II cells (Table 1, Fig. 3). Additionally, in contrast, with the previous work (Domingues et al., 2002), glycerophosphoinositols (PI) were not found in either of both investigated cell forms. This finding is, however, in agreement with an earlier report showing that the genes predicted to be involved in the synthesis of PI are absent from the organism's genome (Sheshadri et al., 2003).

The results show a high variability in the ratio of individual GP classes present in the investigated cells. In phase I cells, 33\% of glycerophosphocholines (PC), 25\% of glycerophosphoethanolamines (PE), 25\% of PA, and 17\% of glycerophosphoglycerols (PG) were detected (Fig. 3). Glycerophosphocholines have a role in the maintenance of cell-membrane integrity and are vital to all of the basic biological processes, especially with formation of cellular energy and intracellular communication or signal transduction (Cronan, 2003). One of the primary roles for PE in bacterial membranes is to spread out the negative charge caused by anionic membrane PL. The PE also enable bacterial multidrug transporters to function properly. They allow the formation of intermediates that are needed for the transporters to properly open and close (Cronan, 2003).

Like previous two PL, PA and PG are important constituents of cell membranes as well. Glycerophosphates play several roles in the functioning of cells being utilized as precursors in the biosynthesis of other lipids, facilitating vesicle fission/fusion via its biophysical properties and acting as a signaling lipids (Athenstaedt and Daum, 1999). Glycerophosphoglycerols also serve as structural components of cell membranes. Furthermore, they are utilized as a precursor for cardiolipin (CL) synthesis (Cronan, 2003; Kuhn et al., 2015).

As shown in Fig. 3, 39\% of PS, $31 \%$ of PC, $15 \%$ of PE, and $15 \%$ of PG were detected in phase II cells. Glycerophosphoserines not found in phase I cells are actively held facing the cytosolic side of the cell membrane by the enzyme flippase (Pomorski and Menon, 2006). This is in contrast to the normal behavior of PL in cell membrane which can freely flip their heads between the two faces of the membrane they comprise. However, when a cell undergoes apoptosis PS are

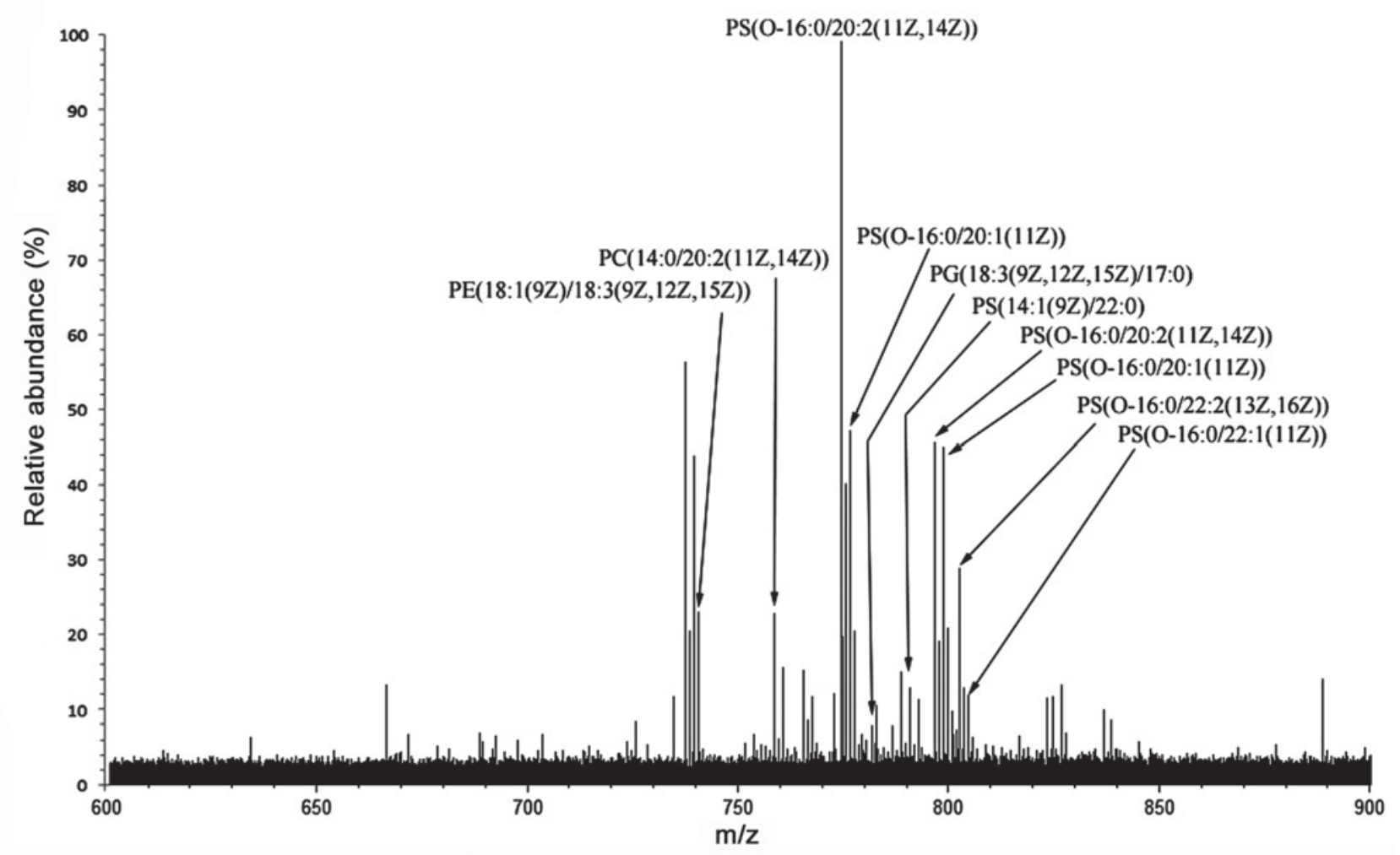

Fig. 2

FT-ICR mass spectrum in the region of $m / z$ 600-900 obtained for chloroform-methanol extract of C. burnetii in low virulent phase II The selected ion peaks are labeled with the Common name as given for GP at http://www.lipidmaps.org/data/databases.html. The peaks represent [M + $\mathrm{H}]^{+},[\mathrm{M}+\mathrm{Na}]^{+}$, and $[\mathrm{M}+\mathrm{K}]^{+}$ions. 
Phase I cells

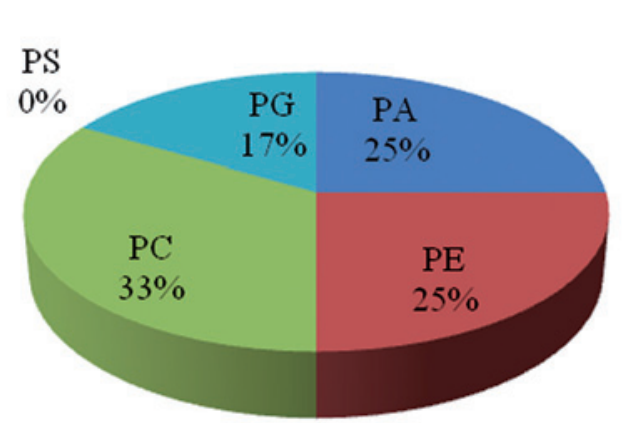

Phase II cells

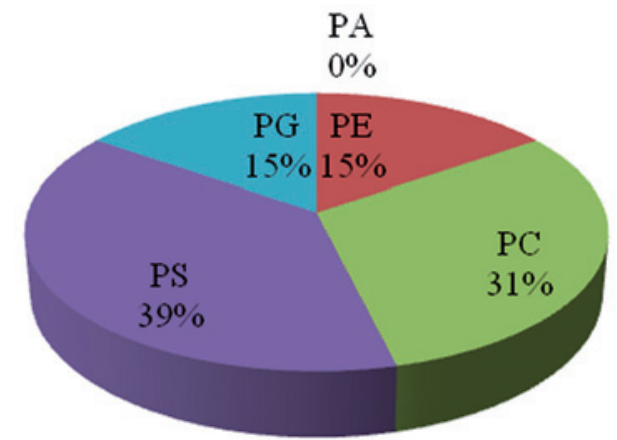

Fig. 3

Relative distribution (in \%) of GP classes in C. burnetii phase I and II cells For abbreviations, see text.

no longer restricted to the cytosolic domain by flippase. When PS naturally flip to the extracellular surface of the cell, they act as a signal for macrophages to engulf the cells (Verhoven et al., 1995).

In this work, we have shown that GP present in the $C$. burnetii outer membrane underwent considerable modifications during the phase variation. This ability is advantageous for the pathogen because a more versatile microorganism can cope better with a variety of different environments. C. burnetii utilizes host cell lipids for membrane biogenesis and possibly energy. In addition, bacterial manipulation of host cell lipid signaling pathways is thought to support the establishment of the intracellular niche (Gilk, 2012). It has been suggested that effectors secreted by the C. burnetii type IV secretion system (Segal et al., 2005) may either directly or indirectly modify host cell lipids (Gilk, 2012). Because PL determine membrane-protein topology, the composition of zwitterionic (e.g., PE) and anionic (e.g., PG and CL) PL in membranes is tightly controlled. Regulation of the bacterial envelope PL composition is suggested to play a critical role in the environmental stability of small cell variant (SCV) versus large cell variant (LCV) forms of C. burnetii, or its ability to grow in the acidic environment of the parasitophorous vacuole (Gilk, 2012). For example, it has been shown that Bacillus stearothermophilus increases the PG and CL content in order to adapt to an acidic environment (Card and Trautman, 1990). C. burnetii contains enzymes for PA head group modifications to form PS, PE, and PG (Gilk, 2012). Our results strongly indicate that these enzymes might become active during the phase variation of the pathogen because PA was found only in phase I and PS in phase II cells (Table 1, Fig. 3).

In conclusion, we have demonstrated an enormous potential of FT-ICR MS combined with Lipid Maps database for rapid and reliable detection of GP in highly complex extraction mixtures of virulent and low virulent cells of $C$. burnetii. For the first time, a more detailed composition and characterization of the individual GP was performed and the role of phase variation on their modifications and compositional changes was demonstrated. Further investigations in this direction, particularly of GP from the SCV and LCV as well as of those isolated from C. burnetii grown under different growth conditions or media might provide an important insight into the basic processes governing the bacterium's development and survival in host cells.

Acknowledgements. The authors gratefully acknowledge the support by the following projects: 2/0144/15 of the Scientific Grant Agency of Ministry of Education of Slovak Republic and the Slovak Academy of Sciences, the APVV-0280-12 and APVV-SK-CZ2013-0215 supported by Agency for Research and Development, 26240220071 of the Research \& Development Operational Programme funded by the ERDF, LO1509 of the Ministry of Education, Youth and Sports of the Czech Republic, CZ.2.16/3.1.00/24023 of the Operational Program Prague-Competitiveness funded by the ERDF, CZ.1.07/2.3.00/30.0003 and CZ.1.05/1.1.00/02.0109 of the Ministry of Education Youth and Sports of the Czech Republic and European Regional Development Funds, and UNCE 204025/2012 of the Charles University.

\section{References}

Arricau-Bouvery N, Rodolakis A (2005): Is Q fever an emerging or re-emerging zoonosis? Vet. Res. 36, 327-349. http:// dx.doi.org/10.1051/vetres:2005010

Athenstaedt K, Daum G (1999): Phosphatidic acid, a key intermediate in lipid metabolism. Eur. J. Biochem. 266, 1-16. http:// dx.doi.org/10.1046/j.1432-1327.1999.00822.x

Baca OG, Paretsky D (1983): Q fever and Coxiella burnetii: a model for host-parasite interactions. Microbiol. Rev. 47, 127-149. 
Card GL, Trautman JK (1990): Role of anionic lipid in bacterial membranes. Biochim. Biophys. Acta 1047, 77-82. http:// dx.doi.org/10.1016/0005-2760(90)90263-W

Cronan JE (2003): Bacterial membrane lipids: where do we stand? Annu. Rev. Microbiol. 57, 203-224. http://dx.doi. org/10.1146/annurev.micro.57.030502.090851

Domingues P, Palkovič P, Toman R (2002): Analysis of phospholipids from Coxiella burnetii by fast atom bombardment mass spectrometry. A rapid method for differentiation of virulent phase I and low virulent phase II cells. Acta Virol. 46, 121-124.

Fodorová M, Vadovič P, Toman R (2011): Structural features of lipid A of Rickettsia typhi. Acta Virol. 55, 31-44. http:// dx.doi.org/10.4149/av 2011 0131

Folch J, Lees M, Sloane Stanley GH (1957): A simple method for the isolation and purification of total lipides from animal tissues. J. Biol. Chem. 226, 497-509.

Gilk SD (2012): Role of lipids in Coxiella burnetii infection. In Toman R, Heinzen RA, Samuel JE, Mege JL (Eds): Coxiella burnetii: Recent advances and new perspectives in research of the Q fever bacterium. Springer Science + Business Media Dordrecht, pp.199-213. http://dx.doi. org/10.1007/978-94-007-4315-1_10

Kraus D, Peschel A (2008): Staphylococcus aureus evasion of innate antimicrobial defense. Future Microbiol. 3, 437-451. http://dx.doi.org/10.2217/17460913.3.4.437

Kuhn S, Slavetinsky CJ, Peschel A (2015): Synthesis and function of phospholipids in Staphylococcus aureus. Int. J. Med. Microbiol. 305, 196-202. http://dx.doi.org/10.1016/j. ijmm.2014.12.016

Marrie TJ, Raoult D (1997): Q fever - a review and issues for the next century. Int. J. Antimicrob. Agents 8, 145-161. http:// dx.doi.org/10.1016/S0924-8579(96)00369-X

McCaul TF, Williams JC (1981): Developmental cycle of Coxiella burnetii: structure and morphogenesis of vegetative and sporogenic differentiations. J. Bacteriol. 147, 1063-1076.

Narasaki CT, Toman R (2012): Lipopolysaccharide of Coxiella burnetii. In Toman R, Heinzen RA, Samuel JE, Mege JL (Eds): Coxiella burnetii: Recent advances and new perspectives in research of the Q fever bacterium. Springer Science + Business Media Dordrecht, pp. 65-90. http:// dx.doi.org/10.1007/978-94-007-4315-1_4
Pomorski T, Menon AK (2006): Lipid flippases and their biological functions. Cell. Mol. Life Sci. 63, 2908-2921. http://dx.doi. org/10.1007/s00018-006-6167-7

Segal G, Feldman M, Zusman T (2005): The Icm/Dot type-IV secretion systems of Legionella pneumophila and Coxiella burnetii. FEMS Microbiol. Rev. 29, 65-81. http://dx.doi. org/10.1016/j.femsre.2004.07.001

Seshadri R, Paulsen IT, Eisen JA, Read TD, Nelson KE, Nelson WC, Ward NL, Tettelin H, Davidsen TM, Beanan MJ, Deboy RT, Daugherty SC, Brinkac LM, Madupu R, Dodson RJ, Khouri HM, Lee KH, Carty HA, Scanlan D, Heinzen RA, Thompson HA, Samuel JE, Fraser CM, Heidelberg JF (2003): Complete genome sequence of the Q-fever pathogen Coxiella burnetii. Proc. Natl. Acad. Sci. USA 100, 5455-5460. http://dx.doi.org/10.1073/ pnas.0931379100

Skultety L, Hajduch M, Flores-Ramirez G, Miernyk JA, Ciampor F, Toman R, Sekeyova Z (2011): Proteomic comparison of virulent phase I and avirulent phase II of Coxiella burnetii, the causative agent of Q fever. J. Proteomics 74, 19741984. http://dx.doi.org/10.1016/j.jprot.2011.05.017

Škultéty L, Toman R, Pätoprstý V (1998): A comparative study of lipopolysaccharides from two Coxiella burnetii strains considered to be associated with acute and chronic Q fever. Carbohydr. Polymers 35, 189-194. http://dx.doi. org/10.1016/S0144-8617(97)00246-4

Strohalm M, Kavan D, Novak P, Volny M, Havlicek V (2010): mMass 3: A cross-platform software environment for precise analysis of mass spectrometric data. Anal. Chem. 82, 4648-4651. http://dx.doi.org/10.1021/ac100818g

Toman R, Škultéty L' (1996): Structural study on a lipopolysaccharide from Coxiella burnetii strain Nine Mile in avirulent phase II. Carbohydr. Res. 283, 175-185. http://dx.doi. org/10.1016/0008-6215(96)87610-5

Toman R, Skultety L, Ihnatko R (2009): Coxiella burnetii glycomics and proteomics- tools for linking structure to function. Ann. N. Y. Acad. Sci. 1166, 67-78. http://dx.doi. org/10.1111/j.1749-6632.2009.04512.x

Verhoven B, Schlegel RA, Williamson P (1995): Mechanisms of phosphatidylserine exposure, a phagocyte recognition signal, on apoptotic T lymphocytes. J. Exp. Med. 182, 1597-1601. http://dx.doi.org/10.1084/jem.182.5.1597 